\title{
Joint line restoration during revision total knee arthroplasty: an accurate and reliable method
}

\author{
Chantal Sadaka, Ziad Kabalan*, Fadi Hoyek, Georges Abi Fares and Jean-Claude Lahoud
}

\begin{abstract}
During revision total knee arthroplasty, the joint line is frequently malpositioned, due to the disappearance of the anatomical landmarks following previous interventions. This leads to decreased clinical outcome and increased risk of re-intervention. Many methods have been proposed to restore the joint line, but none of them has shown itself to be reliable. We describe an accurate and precise method to localize the exact position of the joint line which guarantees a better clinical knee score. The adductor tubercle (AT) is recognized to be the most reliable landmark used to localize the knee joint line (JL). The distance from the AT to the $\mathrm{JL}$ on antero-posterior radiographs (ATJL) and the femoral diameter (FD) on true lateral views were measured on 200 randomly selected normal knees. These measurements were tested for intra- and inter-observer differences. Then, the relationship between these two measurements was studied. A significant correlation and linear regression between FD and ATJL was found $(p<0.001)$, making the adductor tubercle a valid landmark to accurately position the prosthetic joint within $4 \mathrm{~mm}$ from the normal position. No significant difference was noted in the intra and inter-observer measurements ( $F$ test not significant). Sex was found to be an intervening variable $\left(p^{<}\right.$0.001). The correlation and regression between ATJL and FD had to be adjusted accordingly. Once the ATJL was determined preoperatively, the $J \mathrm{~L}$ level is found during surgery by using a caliper that is held on the easily palpable AT. Knowing the femoral diameter, we can easily locate the joint line level surgically, using the adductor tubercle as a landmark. This method leads to better clinical outcomes and a reduced risk of re-intervention following revision total knee arthroplasty.
\end{abstract}

Keywords: Arthroplasty, Knee, Revision prosthesis, Joint line, Adductor tubercle

\section{Background}

The prevalence of total knee arthroplasty (TKA) is increasing exponentially with a more demanding aging population; this leads to an increase of the number of revision total knee arthroplasty (RTKA) (Popa et al. 2014; James and Bono 2005). In fact, in the USA, between the years 1990 and 2000, the prevalence of TKA performed has increased from 138,552 to 308,250 , while the prevalence of RTKA increased from 11,369 to 26,926 (James and Bono 2005). In the year 2011, the number of RTKA performed in the USA $(70,000)$ exceeded by far the number predicted in 2005 for the year $2030(41,432)$ (Popa et al. 2014; James and Bono 2005). This remarkable

\footnotetext{
*Correspondence: ziadkabalan@live.com

Holy Spirit University of Kaslik, Jounieh, Lebanon
}

increase in the prevalence of RTKA stresses the need to adjust the operative planning in order to achieve a better clinical outcome.

A good knee score is directly related to the position of the joint line (Yoshii et al. 1991). The latter is often malpositioned with a more frequent tendency to elevation using the available surgical techniques, especially the ones based on balancing the flexion and extension gaps (Partington et al. 1999; Laskin 2002; Romero et al. 2010), as well as the credos that some surgeons rely on: "two finger breadths above the tibial tubercle"; "at the level of the patellar tip on an extended knee" or " $2 \mathrm{~cm}$ above the fibular head" (Mason et al. 2006). These commonly used methods lack accuracy in positioning the joint line within the narrow acceptable limits of $\pm 8 \mathrm{~mm}$ (Figgie

\section{Springer}

(C) 2015 Sadaka et al. This article is distributed under the terms of the Creative Commons Attribution 4.0 International License (http://creativecommons.org/licenses/by/4.0/), which permits unrestricted use, distribution, and reproduction in any medium, provided you give appropriate credit to the original author(s) and the source, provide a link to the Creative Commons license, and indicate if changes were made. 
et al. 1986; Partington et al. 1999; Laskin 2002), or even $\pm 4 \mathrm{~mm}$ (Hofmann et al. 2006) of the optimal position.

After the disappearance of the anatomical landmarks used for the restoration of the joint line, and knowing the deleterious clinical effect of its malposition, we describe a method that is accurate and reproducible based on the adductor tubercle, the distal femoral landmark that can still be intact after the previous procedures and that is the most reliable landmark for this purpose (Iacono et al. 2013).

\section{Results and discussion}

In order to accurately determine the joint line position using plain radiographs of the prosthetic knee to be revised, we considered two radiographic measurements: ATJL and FD.

The one-way ANOVA test did not reveal a significant difference ( $F$ test not significant) in the intra and interobserver reliability of the ATJL and FD measurements (Table 1). These findings are identical to Clement et al. (2014) who also proved the reliability of the FD measurement, as well as Iacono et al. (2013) and Maderbacher et al. Maderbacher et al. 2014) who confirmed likewise the reliability of the ATJL measurement. In addition, Romero et al. (2010) had similar findings concerning distal femoral measurements.

Sex was found to be highly related to ATJL $\left[\mathrm{F}_{(\mathrm{df}=1 ; 198)}=158.89 ; \mathrm{p}<0.001\right]$ and to $\mathrm{FD}$ $\left[\mathrm{F}_{(\mathrm{df}=1 ; 198)}=78.15 ; \mathrm{p}<0.001\right]$. Therefore, after stratifying by sex as a confounding variable, the following strong correlations and regressions were found between ATJL and FD: For female patients (Fig. 1): ATJL $=0.66 \mathrm{FD}+27.21$

Table 1 Results of the one-way ANOVA test for the reliability of the measurements: $F$ values and $p$ values of the oneway ANOVA test, done on the $\mathbf{4 0}$ female and $\mathbf{4 0}$ male knee measurements (ATJL and FD) taken by the first observer twice and by the two other observers, in order to test for the intra- and inter-observer reliability of these measurements

\begin{tabular}{lll}
\hline $\begin{array}{l}\text { Measurements tested for intra- } \\
\text { and inter-observer differences }\end{array}$ & $\mathbf{F}_{\text {(df=3;36) }}$ & $\mathbf{p}$ value \\
\hline Female ATJL & 0.02 & 0.997 \\
Male ATJL & 0.03 & 0.992 \\
Female FD & 0.07 & 0.974 \\
Male FD & 0.19 & 0.900 \\
\hline
\end{tabular}

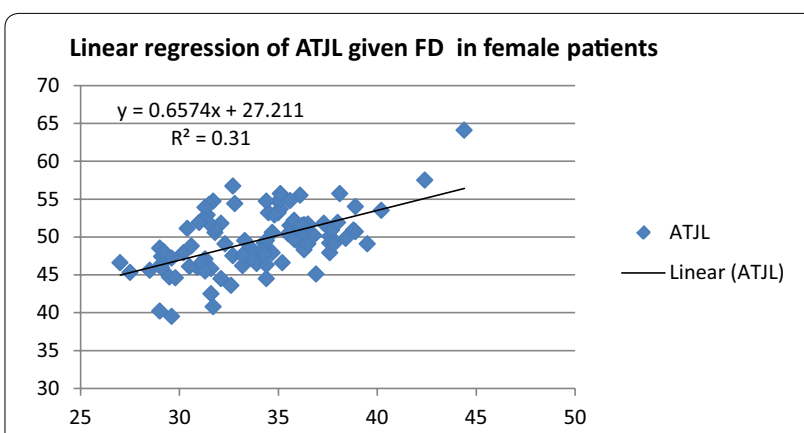

Fig. 1 Graph showing the linear regression of ATJL in function of FD in female patients: ATJL $=0.657 \mathrm{FD}+27.211$. The coefficient of determination $R^{2}$ is also mentioned

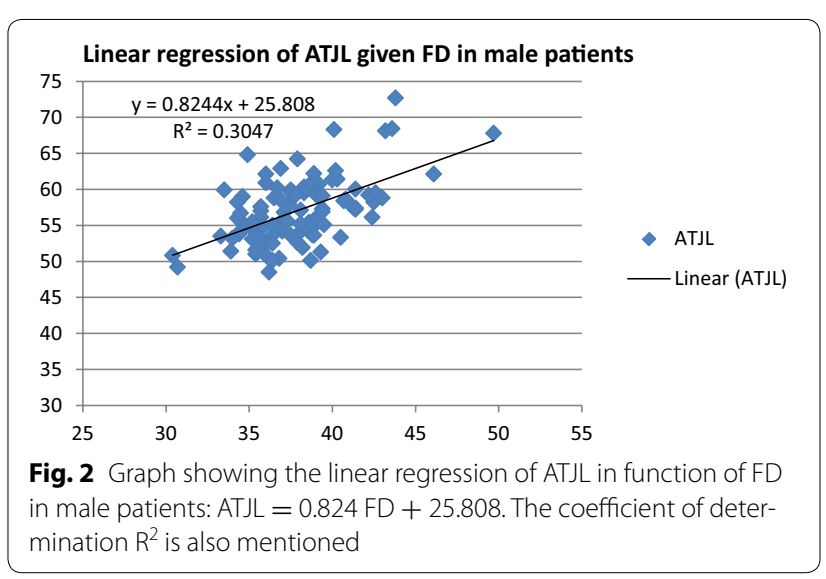

$\left[\mathrm{F}_{(\mathrm{df}=1 ; 98)}=44.03 ; \mathrm{p}<0.001\right]$; and for men (Fig. 2): $\mathrm{ATJL}=0.82 \mathrm{FD}+25.81\left[\mathrm{~F}_{(\mathrm{df}=1 ; 98)}=42.95 ; \mathrm{p}<0.001\right]$.

Using these formulas, the difference between expected and observed values was limited to $4 \mathrm{~mm}$ in $78 \%$ of women and $74 \%$ of men, and to $8 \mathrm{~mm}$ in $99 \%$ of women and $97 \%$ of men, proving therefore the high precision of our method in localizing the JL within the narrow acceptable limits of the literature (Figgie et al. 1986; Partington et al. 1999; Laskin 2002). In fact, a cadaveric study has shown that the restoration of the joint line after total knee replacement ensures the normal function of the knee (Yoshii et al. 1991). In addition, the restoration of the joint line guarantees symmetrical flexion and extension gaps, which in turn, warrants knee stability (Hofmann et al. 2006). Figgie et al., based on the modified Mayo Clinic Knee score, as well as Partington et al. who used the Knee Society Score (KSS), demonstrated that 
an elevation of the joint line of more than $8 \mathrm{~mm}$ from its optimal position yielded deleterious clinical outcomes (Figgie et al. 1986; Partington et al. 1999). A newer study showed that the acceptable deviation of the joint line from its normal position is restricted to the interval of $4 \mathrm{~mm}$ of elevation or depression, in order to obtain the optimal clinical results (Laskin 2002).

Once the ATJL is determined preoperatively, the magnification error needs correction. This can be simply done by using a radiology ruler. It can also be done by calculating the magnification ratio between the radiologic and the intra-operative measurement of a segment of the prosthesis to be removed. When the real ATJL distance is known, a caliper can be easily placed on the adductor tubercle and the joint line level will be determined so that the appropriate augment sizes can be selected to restore the bone loss (Fig. 3).

\section{Conclusions}

The restoration of the joint line level during a revision total knee arthroplasty has a major positive effect on the clinical outcome, which leads to reduced risks of re-intervention and precocious complications. No described method showed itself reliable enough to become a standard. The method we described proved itself to be accurate, reproducible, reliable and easily applicable for planning a successful revision total knee arthroplasty.

\section{Methods}

The study design is a level III therapeutic study. The sample was selected from our institution's database Picture Archiving and Communication System (PACS) at Notre Dame de Secours University Hospital and included 200 knee radiographs that fulfill the following inclusion criteria:

- 100 radiographs of each gender

- Normal knee

- True lateral view

- Good antero-posterior (AP) view

- Age between 20 and 50 years.

Meniscal and ligamentous disorders were not considered as exclusion criteria.

Two measurements were done on each knee:

1. On the AP view we measured the distance from the adductor tubercle to the joint line, ATJL.

2 . On the lateral view the femoral diameter was measured at the level of the flare of the posterior condyle, FD (Fig. 4).

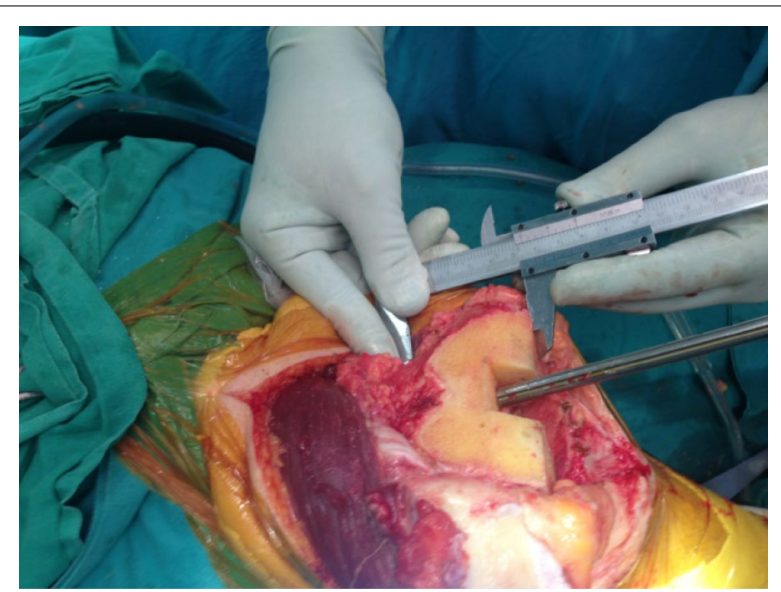

Fig. 3 Per-operative ATJL determination: per-operative determination of the adductor tubercle during a revision total knee arthroplasty, and the measurement taken from this landmark to the distal femoral cut. The corresponding measurement will be subtracted from the calculated ATJL, in order to find the corresponding thickness of the prosthesis and augments to be inserted

The adductor tubercle was identified on the AP knee radiographs as the most prominent bony protuberance at the summit of the medial condyle.

A first observer, an orthopedic surgeon took the measurements on the 200 radiographs and then repeated them after 2 weeks for 40 male knees and 40 female knees in order to test the method for intra-observer difference. In order to account for inter-observer differences, a radiology resident took measurements on the same 40 male and 40 female knees as a second observer and investigator involved in the making of the study. Then, these same measurements were also taken by a third person, a last year medical student that is completely blind to the study.

The one-way ANOVA test was employed to study the reliability of the intra and inter-observer measurements of FD and ATJL for each gender $\left(\mathrm{F}_{\text {critical }(\mathrm{df}=3 ; 36)}=2.87\right.$; $\alpha=0.05)$.

Sex was tested for its effect as an intervening variable. Two simple linear regressions were drawn between sex and FD and between sex and ATJL, in order to determine the presence of a statistically significant relationship between sex and these two variables $\left(\mathrm{F}_{\text {critical }}(\mathrm{df}=1\right.$; $\left.{ }_{198)}=3.89 ; \alpha=0.05\right)$. After controlling for gender variation, the two measurements done for each knee were studied for correlation, followed by determining the linear regression accordingly $\left(\mathrm{F}_{\text {critical }}(\mathrm{df}=1 ; 98)=3.94\right.$; $\alpha=0.05)$.

Intra-operatively, the adductor tubercle serves as a landmark. It is determined as the most prominent bony 

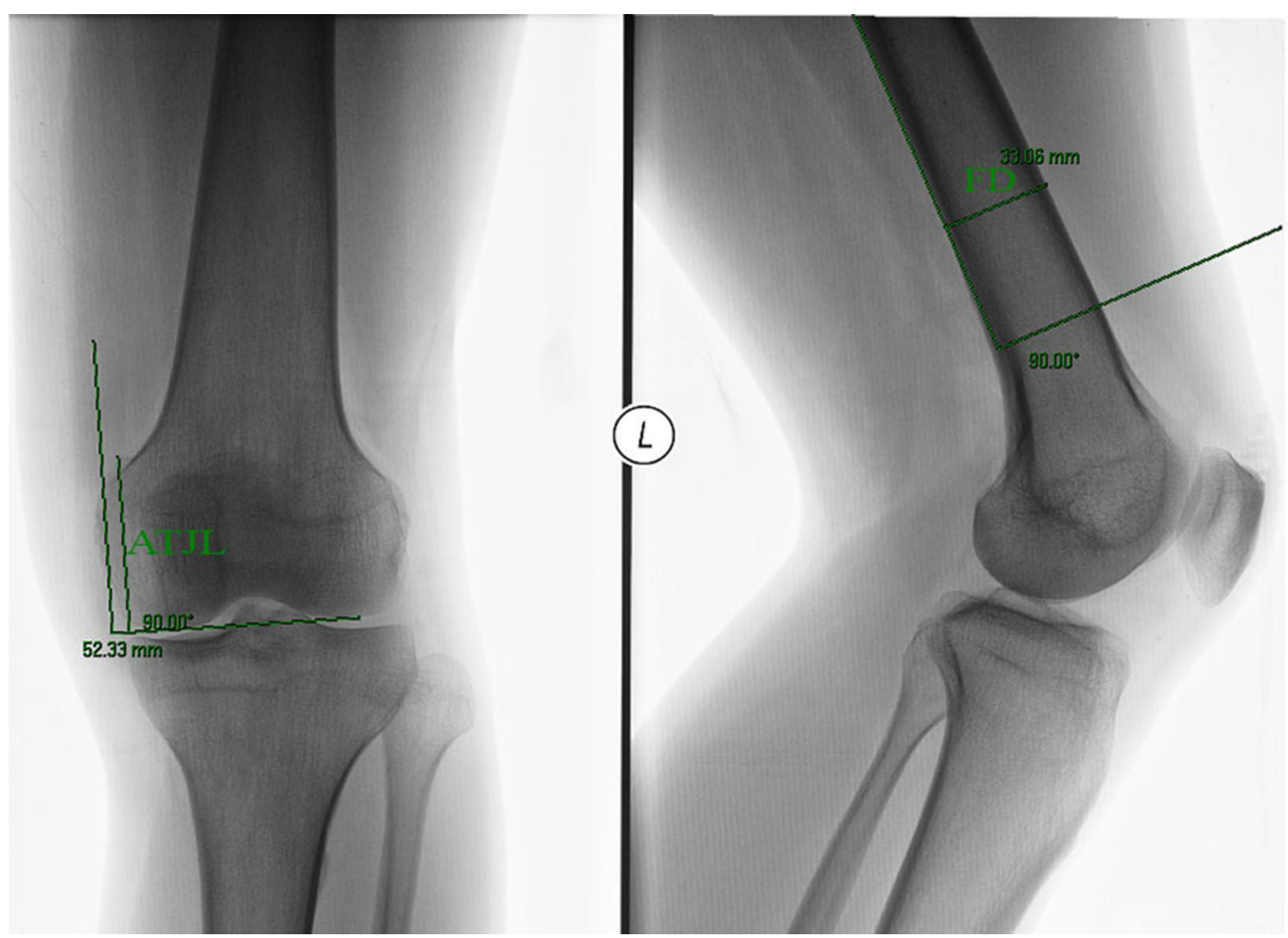

Fig. 4 The two radiologic measurements: on the AP view, the distance ATJL from the adductor tubercle to the joint line was measured. On the lateral view, the femoral diameter FD was measured at the level of the flare of the posterior condyle

protuberance on the medial aspect of the distal femur. It can also be palpated at the insertion of the adductor magnus muscle.

\section{Abbreviations}

AT: adductor tubercle; JL: joint line; ATJL: the distance from the Adductor Tubercle to the Joint Line; FD: the femoral diameter measured on the lateral view at the level of the flare of the posterior condyle; TKA: total knee arthroplasty; RTKA: revision total knee arthroplasty; KSS: Knee Society Score; PACS: picture archiving and communication system; AP: antero-posterior.

\section{Authors' contributions}

CS and ZK are the first authors who reviewed the literature, chose the variables, gathered the data, did the statistical analysis, interpreted and discussed the results. FH supervised the work and gave the authors the advice concerning the applicability of this method. GAF was the advisor and a contributor in the statistical analysis. JCL came out with the original idea of the study and helped in the verification of the surgical applicability of the method. All authors read and approved the final manuscript.

\section{Acknowledgements}

We thank Mr. Assaad Sadaka, Mrs. Rosaline Nawfal and Dr. Khouzama Hijal Shaar for the support in the statistical analysis. We thank Ms. Marie-Ange Kassir for being the third observer.

\section{Competing interests}

The authors declare that they have no competing interests.

Received: 20 May 2015 Accepted: 18 November 2015

Published online: 26 November 2015

\section{References}

Clement ND, Hamilton DF, Burnett R (2014) A technique of predicting radiographic joint line and posterior femoral condylar offset of the knee. Arthritis 2014:121069. doi:10.1155/2014/121069

Figgie HE, Goldberg VM, Heiple KG et al (1986) The influence of tibialpatellofemoral location on function of the knee in patients with the posterior stabilized condylar knee prosthesis. J Bone Joint Surg Am 68:1035-1040

Hofmann AA, Kurtin SM, Lyons S et al (2006) Clinical and radiographic analysis of accurate restoration of the joint line in revision total knee arthroplasty. J Arthroplasty 21:1154-1162. doi:10.1016/j.arth.2005.10.026

lacono F, Lo Presti M, Bruni D et al (2013) The adductor tubercle: a reliable landmark for analysing the level of the femorotibial joint line. Knee Surg Sports Traumatol Arthrosc 21:2725-2729. doi:10.1007/ s00167-012-2113-4

James V, Bono M (2005) Revision Total Knee Arthroplasty. Springer-Verlag, New York

Laskin RS (2002) Joint line position restoration during revision total knee replacement. Clin Orthop Relat Res. doi:10.1097/01. blo.0000030494.43495.e4

Maderbacher G, Keshmiri A, Schaumburger J et al (2014) Accuracy of bony landmarks for restoring the natural joint line in revision knee surgery: an MRI study. Int Orthop 38:1173-1181. doi:10.1007/s00264-014-2292-3

Mason M, Belisle A, Bonutti P et al (2006) An accurate and reproducible method for locating the joint line during a revision total knee arthroplasty. J Arthroplasty 21:1147-1153. doi:10.1016/j.arth.2005.08.028

Partington PF, Sawhney J, Rorabeck CH, Barrack RL, Moore J (1999) Joint line restoration after revision total knee arthroplasty. Clin Orthop Relat Res (367):165-171

Popa MA, Wera GD, Goldberg VM (2014) Surgical management of the unstable total knee arthroplasty. AAOS. http://www.aaos.org/news/aaosnow/ may14/clinical6.asp 
Romero J, Seifert B, Reinhardt O et al (2010) A useful radiologic method for preoperative joint-line determination in revision total knee arthroplasty. Clin Orthop Relat Res 468:1279-1283. doi:10.1007/s11999-009-1114-1
Yoshii I, Whiteside LA, White SE, Milliano MT (1991) Influence of prosthetic joint line position on knee kinematics and patellar position. J Arthroplasty 6:169-177. doi:10.1016/S0883-5403(11)80013-6

\section{Submit your manuscript to a SpringerOpen ${ }^{\odot}$} journal and benefit from:

- Convenient online submission

- Rigorous peer review

- Immediate publication on acceptance

- Open access: articles freely available online

- High visibility within the field

- Retaining the copyright to your article

Submit your next manuscript at $\boldsymbol{\wedge}$ springeropen.com 